\title{
Police killings of Black people and rates of sexually transmitted infections: a cross-sectional analysis of 75 large US metropolitan areas, 2016
}

\author{
Umedjon Ibragimov (1) , 'Stephanie Beane, ${ }^{1}$ Samuel R Friedman, ${ }^{2}$ Justin C Smith, \\ Barbara Tempalski, ${ }^{2}$ Leslie Williams, ${ }^{2}$ Adaora A Adimora, ${ }^{3,4}$ Gina M Wingood, ${ }^{5}$ \\ Sarah McKetta, ${ }^{6}$ Ronald D Stall, ${ }^{7}$ Hannah LF Cooper ${ }^{1}$
}

\begin{abstract}
- Additional material is published online only. To view please visit the journal online (http://dx.doi.org/10.1136/ sextrans-2019-054026)

For numbered affiliations see end of article.
\end{abstract}

\section{Correspondence to} Dr Umedjon Ibragimov, Emory University School of Public Health, Atlanta, GA 30322, USA; umed.ibragimov@emory. edu

Received 5 March 2019 Revised 23 July 2019

Accepted 12 August 2019 Published Online First 23 August 2019
Check for updates

(C) Author(s) (or their employer(s)) 2020. No commercial re-use. See rights and permissions. Published by BMJ.

To cite: Ibragimov $U$ Beane S, Friedman SR, et al. Sex Transm Infect 2020;96:429-431

\begin{abstract}
Objectives Emerging literature shows that racialised police brutality, a form of structural racism, significantly affects health and well-being of racial/ethnic minorities in the USA. While public health research suggests that structural racism is a distal determinant of sexually transmitted infections (STIs) among Black people, no studies have empirically linked police violence to STIs. To address this gap, our study measures associations between police killings and rates of STIs among Black residents of US metropolitan statistical areas (MSAs).

Methods This cross-sectional ecological analysis assessed associations between the number of Black people killed by police in 2015 and rates of primary and secondary syphilis, gonorrhoea and chlamydia per 100000 Black residents of all ages in 2016 in 75 large MSAs. Multivariable models controlled for MSA-level demographic and socioeconomic characteristics, police expenditures, violent crime, arrest and incarceration rates, insurance rates and healthcare funding.

Results In 2015, the median number of Black people killed by police per MSA was 1.0. In multivariable models, police killings were positively and significantly associated with syphilis and gonorrhoea rates among Black residents. Each additional police killing in 2015 was associated with syphilis rates that were $7.5 \%$ higher and gonorrhoea rates that were $4.0 \%$ higher in 2016 . Conclusions Police killings of Black people may increase MSA-level risk of STI infections among Black residents. If future longitudinal analyses support these findings, efforts to reduce STIs among Black people should include reducing police brutality and addressing mechanisms linking this violence to STIs.
\end{abstract}

\section{INTRODUCTION}

In 2018, the American Public Health Association recognised police brutality as a public health issue that disproportionately affected the health of racial/ethnic minorities and other marginalised populations. ${ }^{1}$ A growing line of research suggests that racialised police brutality, a form of structural racism, has many adverse consequences for the public's health, ${ }^{2}$ both among its immediate targets and also among witnesses and the broader communities in which these targets and witnesses live. For instance, Bor et al found that the number of police killings of Black men in a state was associated with more poor mental health days among Black adults living in that state. ${ }^{3}$ The same study found no association between police killings of Black people and White residents' mental health. This is one more argument supporting the racialised nature of police brutality's effects on public health.

The present analysis investigates whether police killings of Black people in a metropolitan statistical area (MSA) are associated with rates of sexually transmitted infections (STIs) among Black adults and adolescents living in that MSA. We chose to focus on this outcome because of the high and rising burden of STIs among Black people, ${ }^{4}$ demonstrated link between structural racism and STIs, ${ }^{5}$ and because multiple plausible pathways may link police killings to STI transmission in this population. For example, studies of non-police-related violence suggest ${ }^{6}$ that psychological distress may lead to risky sexual practices. This analysis was guided by the HIV Ecology Model, ${ }^{7}$ which posits that racism and other distal processes shape sexual networks and behaviours, and the Minority Stress Model, ${ }^{8}$ which links the oppression of minority groups by a dominant majority to stress that adversely affects minority health.

\section{METHODS}

This analysis is part of a larger cohort study of large US MSAs with populations >500000 in 1990 $(n=96)$. Complete data were available for 75 of 96 MSAs that met this criterion (data for crime and arrest covariates were missing for 21 MSAs).

\section{Measures}

Outcome

The Centers for Disease Control and Prevention (CDC) provided data on the rates of newly diagnosed cases of (1) primary and secondary syphilis, (2) gonorrhoea and (3) chlamydia among non-Hispanic Black residents per 100000 Black residents of each MSA in 2016. See online supplementary table S1 for details.

\section{Primary exposure}

Data on the number of non-Hispanic Black people killed by police in 2015 were culled from The 
Guardian's The Counted database. This newspaper collected these data from police reports, witness statements, media coverage, research accounts and open-source projects reporting police killings. Because we conceptualised police killings as major events, like terrorist attacks, consistent with past research on police killings, ${ }^{3}$ we operationalised the exposure as a count. Since the purpose of our analysis is to explore the effect of racialised police killings as part of structural racism, we focus on police killings of Black people only. We evaluated killings occurred in 2015, 1 year before the outcome, because we anticipated that the exposure's effects might not be instantaneous.

\section{Confounders}

We included variables capturing MSA sociodemographic composition, war on drugs-related criminal justice implementation, economic characteristics, health insurance rates and government expenditures that might confound the relationship between fatal police encounters and STIs (see online supplementary table S1 for the list of covariates and details on data sources).

\section{Analysis}

Measures of central tendency and dispersion described variable distributions. We natural-log transformed the number of fatal police encounters (for all models) and syphilis rates to linearise relationships (gonorrhoea and chlamydia rates were not log transformed; see online supplementary table S4 for description of coefficient back transformation). To build each multivariable model (one for each STI outcome), we first identified variables that might confound the police killings/STI relationship by adding one putative confounder at a time to a bivariate model containing the police killings variable and the outcome; variables that altered the magnitude of this focal relationship by $>10 \%$ were included in the preliminary multivariable model. ${ }^{9}$ We removed potential confounders from the preliminary multivariable model that were collinear, as determined by condition index and variance proportion multicollinearity diagnostics. Our cohort is a census of large US MSAs, not a sample, so p-values hold little meaning. Instead of using $\mathrm{p}<0.05$ to determine statistical significance, we defined substantive significance as the magnitude of the standardised coefficient $\geq|0.1| \cdot{ }^{10}$ All models included a state covariate to account for attributes of states that may impact our outcome. To aid interpretation, we calculated the difference in the median STI rates corresponding to one unit difference in the number of killings (see online supplementary table S4 for details).

\section{RESULTS}

The median number of fatal encounters with police among Black people in these MSAs in 2015 was 1.0 (25th percentile: $0.0,75$ th percentile: 3.0 ; see online supplementary table S2 for descriptive statistics).

\section{Syphilis}

In the multivariable model, the magnitude of the relationship between the log of fatal encounters and the logged syphilis rates was $b=0.17$ (standardised $B>0.1$; table 1 ), indicating that MSAs that had one more police killing of a Black person in 2015 had a 7.5\% higher rate of syphilis among Black residents in 2016 (online supplementary table S4).

\section{Gonorrhoea}

In the multivariable model, the magnitude of the relationship between $\log$ of fatal encounters and the gonorrhoea rate was $\mathrm{b}=39.36$ (standardised $\mathrm{B}>0.1$; table 1 , suggesting that MSAs with 1 more police killing of a Black person in 2015 had a 4.0\% higher rate of gonorrhoea among Black residents in 2016 (online supplementary table S4). This relationship only emerged after controls were included (bivariate relationship: $\mathrm{B}=-0.08$; (table 1).

\section{Chlamydia}

In the multivariable model, there was no substantively significant relationship between police killings and chlamydia rates $(\mathrm{B}=0.02)$.

\section{DISCUSSION}

Our exploratory multivariable analyses indicate that the number of police killings of Black residents of an MSA is positively associated with the annual rates of syphilis and gonorrhoea among Black residents of that MSA. Our results align with the HIV Ecology Model, Minority Stress Model, conceptual work on

Table 1 Results of bivariate and multivariate analyses regressing rates of sexually transmitted infections among Black people (per 100 000) on logged no. Black peopleๆ killed by police in 75 large MSAs-2016*

\begin{tabular}{|c|c|c|c|c|}
\hline \multirow[b]{2}{*}{ Models by outcome } & \multirow{2}{*}{$\begin{array}{l}\text { Bivariate } \\
\text { Standardised } \\
\mathrm{B}(\mathrm{Cl})\end{array}$} & \multicolumn{3}{|l|}{ Multivariablet } \\
\hline & & $\begin{array}{l}\text { Standardised } \\
\mathrm{B}(\mathrm{Cl})\end{array}$ & $\begin{array}{l}\text { Unstandardised, } \\
\mathrm{B}(\mathrm{CI})\end{array}$ & $\begin{array}{l}\text { Per cent increase in the median STI } \\
\text { rate per } 1 \text { unit increase in the mean no. } \\
\text { Black persons killed by police }\end{array}$ \\
\hline Logged syphilis rateł & $0.07(-0.25$ to 0.39$)$ & $0.14 \S(-0.41$ to 0.70$)$ & $0.17 \S(-0.31$ to 0.65$)$ & $7.5 \%$ \\
\hline Gonorrhoea rate & $-0.08(-0.37$ to 0.21$)$ & $0.14 \S(-0.30$ to 0.57$)$ & $39.36 \S(-85.6$ to 164.3$)$ & $4.0 \%$ \\
\hline Chlamydia rate & $-0.16 \S(-0.42$ to 0.10$)$ & $0.02(-0.4$ to 0.45$)$ & 13.06 (-210.0 to 237.0$)$ & $0.5 \%$ \\
\hline
\end{tabular}

Bivariate and multivariable models include state covariate.

*The outcome is 2016 STI data. We lagged covariates 1-2 years because we did not expect an instantaneous effect on the outcome.

†Multivariable models controlled for MSA-level covariates selected at bivariate stage among demographic (total and Black population size, population density, \% of population aged 15-29, Black adults sex ratio, Black isolation index, \% female-headed households), socioeconomic (Gini index, affordable housing; Black population status and Black/ White disparity in employment, poverty and educational attainment), criminal justice and policing (police per 1000 population, hard drug arrest rate, violent crime rate, police expenditures per capita, \% incarcerated) and access to services (insurance rate, Government expenditures on health and on housing and community development) domains. See online supplementary table $\mathrm{S} 4$ for the list of covariates selected for each model and their bivariate and multivariable model parameters.

¥Variable's distribution was skewed and natural log transformed to approximately conform to the normal distribution.

§Significant at the a priori level. Confounders proceeded to the next stage of analysis, the multivariate model, if they changed the no. Black people killed by police/STI

relationship by $>10 \%$ in bivariate models. In the multivariate model, the criteria for substantive significance was a standardised coefficient $\geq|0.10|$.

IVariable natural log transformed to linearie its relationship with the outcome.

MSA, metropolitan statistical area; STI, sexually transmitted infection. 
the adverse impacts of structural racism and police brutality on health, ${ }^{2}$ and empirical studies linking structural racism to STIs among Black people. ${ }^{5}$ Police killings may increase STI rates through multiple mechanisms. They may elevate psychological stress and trauma, which in turn may generate riskier sexual practices. Police killings may also reinforce Black people's distrust of institutions and fear of racist encounters at or on the way to healthcare providers, which may limit their access to services and generate higher background STI prevalence in sexual networks.

Findings should be interpreted with caution. The study's ecological and cross-sectional design do not support causal inference. Our findings have limited generalisability to smaller MSAs or non-urban areas. Though we analysed the most accurate nationwide data on the focal exposure and outcomes, these measures were still limited. The relationships found here may vary by individual characteristics (eg, age, gender, social class, sexual orientation), but we were unable to explore these possibilities because the CDC would not release STI data by MSA, year and more than one demographic characteristic. Potential underreporting of police Black killings and STIs might have biased findings. Excluding $21 \mathrm{MSAs}$ due to missing crime and arrest data might have attenuated the strength of the focal associations: these MSAs had 50\% higher median number of police killings and higher median STI rates (33\% for syphilis, $45 \%$ for gonorrhoea and 21\% for chlamydia) than MSAs included to the analysis. Due to the large number of covariates the models are specific to our data and have limited generalisability to other MSAs.

\section{CONCLUSION}

This cross-sectional ecological study is a first step in investigating the possible impacts of police brutality on STIs. More conclusive studies would be possible with longitudinal data on various types of police brutality, and individual-level data on STI status, age, gender, sexual orientation and social class. Further studies should assess mechanisms linking police brutality to STIs. Advancing research on the adverse health impacts of police brutality can support advocacy efforts by public health professionals and civil rights activists to reduce police brutality—both an important social justice issue and, as emerging evidence testifies, a powerful structural determinant of health.

\footnotetext{
Author affiliations

'Behavioral Sciences and Health Education, Emory University School of Public Health, Atlanta, Georgia, USA

${ }^{2}$ National Development and Research Institutes, New York City, New York, USA

${ }^{3}$ Department of Epidemiology, Gillings School of Global Public Health, University of North Carolina at Chapel Hill, Chapel Hill, North Carolina, USA

${ }^{4}$ Division of Infectious Diseases, School of Medicine, University of North Carolina at Chapel Hill, Chapel Hill, North Carolina, United States

${ }^{5}$ Department of Sociomedical Sciences, Mailman School of Public Health, Columbia University, New York City, New York, USA
}

${ }^{6}$ Department of Epidemiology, Mailman School of Public Health, Columbia University, New York City, New York, United States

${ }^{7}$ Department of Behavioral and Community Health Sciences and Department of Infectious Diseases and Microbiology, Graduate School of Public Health, University of Pittsburgh, Pittsburgh, Pennsylvania, USA

\section{Handling editor Alec Miners}

Acknowledgements We express our gratitude to the US Centers for Disease Control and Prevention for sharing STD Case Surveillance data from the National Notifiable Disease Surveillance System.

Contributors UI conceptualised the study, contributed to the study methodology and led the writing. SB conducted the analyses and contributed to writing. SF conceptualised the study, reviewed and edited the manuscript; JCS, BT, LW and GW contributed to the study methodology, reviewed and edited the manuscript. AA, SM and RS reviewed and edited the manuscript. HLFC conceived the study, contributed to the study methodology, cowrote the manuscript and supervised the study.

Funding The following grants supported this project: National Institute on Drug Abuse, National Institutes of Health (DA037568; PIs: Cooper, Friedman and Stall); Center for AIDS Research at Emory University (P30AI050409; PI: Del Rio) and Center for Drug Use and HIV Research (P30 DA11041; PI Sherry Deren).

Disclaimer The findings and conclusions in this report are those of the authors and do not necessarily represent the official position of the Centers for Disease Control and Prevention.

Competing interests None declared.

Patient consent for publication Not required.

Provenance and peer review Not commissioned; externally peer reviewed.

\section{ORCID iD}

Umedjon Ibragimov http://orcid.org/0000-0001-7111-2139

\section{REFERENCES}

1 American Public Health Association. New American public health association policy statements address gun suicides, tuberculosis prevention, global food security and more, 2018. Available: https://www.apha.org/news-and-media/news-releases/aphanews-releases/2018/2018-policy-statements

2 Alang S, McAlpine D, McCreedy E, et al. Police brutality and black health: setting the agenda for public health scholars. Am J Public Health 2017;107:662-5.

3 Bor J, Venkataramani AS, Williams DR, et al. Police killings and their spillover effects on the mental health of black Americans: a population-based, quasi-experimental study. Lancet 2018;392:302-10.

4 Centers for Disease Control and Prevention. Sexually transmitted diseases surveillance 2017. STDs in racial and ethnic minorities., 2018. Available: https://www.cdc.gov/std/ stats 17/minorities.htm [Accessed November 10, 2018].

5 Biello KB. Residential racial segregation and disparities in sexually transmitted disease risk in the United States: the growing evidence. Sex Transm Dis 2013;40:444-6.

6 Cavanaugh CE, Hansen NB, Sullivan TP. Hiv sexual risk behavior among low-income women experiencing intimate partner violence: the role of posttraumatic stress disorder. AIDS Behav 2010;14:318-27.

7 Buot M-LG, Docena JP, Ratemo BK, et al. Beyond race and place: distal sociological determinants of HIV disparities. PLoS One 2014;9:e91711.

8 Meyer IH. Prejudice, social stress, and mental health in lesbian, gay, and bisexual populations: conceptual issues and research evidence. Psychol Bull 2003;129:674-97.

9 Lee $\mathrm{PH}$. Is a cutoff of 10\% appropriate for the change-in-estimate criterion of confounder identification? J Epidemiol 2014;24:161-7.

10 Cooper HLF, Brady JE, Friedman SR, et al. Estimating the prevalence of injection drug use among black and white adults in large U.S. metropolitan areas over time (1992-2002): estimation methods and prevalence trends. J Urban Health 2008;85:826-56. 